\title{
Ácidos graxos trans em óleos vegetais refinados poli-insaturados comercializados no estado de São Paulo, Brasil
}

\author{
Trans fatty acids in refined polyunsaturated vegetable oils commercialized in the city of São Paulo, Brazil
}

Sabria AUED-PIMENTEL ${ }^{1 \star}$, Edna Emy KUMAGAI ${ }^{1}$, Mahyara Markievicz Mancio KUS ${ }^{1}$, Miriam Solange Fernandes CARUSO ${ }^{1}$, Mário TAVARES², Odair ZENEBON ${ }^{1}$

\begin{abstract}
Resumo
Neste trabalho são apresentados os resultados da composição de ácidos graxos, principalmente trans, de óleos vegetais poli-insaturados refinados, coletados no comércio do estado de São Paulo entre os anos de 2005 e 2007. Foram analisadas 34 amostras de óleo de soja, 7 de girassol, 2 de canola e 6 de milho. Os ésteres metílicos de ácidos graxos foram preparados por transesterificação alcalina a frio e analisados por cromatografia gasosa em coluna capilar de 100 m (SP 2560), após a otimização das condições analíticas. Dezesseis amostras de óleo de soja, duas de canola e quatro de girassol apresentaram níveis de ácidos graxos trans acima de 2,0\% (p/p de ésteres metílicos). De acordo com a Resolução RDC 360/2003 da ANVISA/MS, é obrigatória a declaração dos níveis de ácidos graxos trans na rotulagem dos alimentos embalados quando os teores forem superiores a $0,2 \mathrm{~g}$ na porção do alimento. No caso de óleos vegetais, a porção é de $13 \mathrm{~mL}$ (uma colher de sopa) e, portanto, na rotulagem nutricional de várias amostras deverá constar valor superior a zero. A melhoria no processo de refino dos óleos vegetais insaturados como soja, canola e girassol, pelo controle das temperaturas de desodorização, poderá contribuir para atender às recomendações da Organização Mundial de Saúde, no sentido de minimizar os níveis de ácidos graxos trans dos alimentos preservando a saúde da população.
\end{abstract}

Palavras-chave: ácidos graxos trans; óleos vegetais refinados; legislação brasileira; rotulagem nutricional.

\begin{abstract}
This paper describes the results of fatty acids composition, mainly trans, in refined polyunsaturated vegetable oils, commercialized in the city of São Paulo, Brazil during the years 2005 and 2007. The following samples were analyzed: 34 of soybean oil, 7 of sunflower oil, 2 of canola, and 6 of corn oil. The fatty acids were transesterified in a cold process and analyzed with optimized conditions by gas chromatography in a 100 m capillary column (SP 2560). Sixteen samples of soybean, two of canola, and four of sunflower oil showed levels of trans fatty acids higher than 2.0\% (w/w methyl ester). In accordance with RDC 360/2003 of the Brazilian Sanitary Survey Agency (ANVISA), the trans fatty acid content must be on the nutrition facts label all food labels. Samples with less than $0.2 \mathrm{~g}$ of trans fatty acids per serving are considered free of them. The serving for vegetable oil is $13 \mathrm{~mL}$. Therefore, the label of several vegetable oil samples analyzed should contain levels of trans fatty acids higher than zero. The vegetable oil refining process improvement, like the controlling of deodorization temperature, could contribute to meet the recommendations of the World Health Organization to minimize the trans fatty acids levels in food and to preserve the population health.
\end{abstract}

Keywords: trans fatty acid; refined polyunsaturated vegetable oils; Brazilain legislation; nutritional labeling.

\section{Introdução}

De acordo com a RDC 360/2003 da ANVISA - Agência Nacional de Vigilância Sanitária, é obrigatória a declaração dos níveis de ácidos graxos trans na rotulagem dos alimentos embalados no Brasil (MINISTÉRIO DA SAÚDE, 2003a). As informações nutricionais, na rotulagem dos alimentos, contribuem para a escolha de dietas mais saudáveis. A ingestão inadequada de ácidos graxos trans pode aumentar o risco das doenças cardiovasculares, as quais são a principal causa de morte no mundo (MOZAFFARIAN et al., 2006; HAWKE, 2004; OMS, 2003).

Cerca de $80 \%$ dos ácidos graxos trans da dieta provêm das gorduras parcialmente hidrogenadas, obtidas em processo industrial de hidrogenação de óleos vegetais insaturados, como óleo de soja. Na hidrogenação, os isômeros predominantes são monoenoicos cis e trans formados pela migração e isomerização das duplas ligações. Entretanto, os ácidos graxos trans podem ocorrer naturalmente, em pequenas quantidades, na gordura de animais ruminantes (leite e carne), sendo formados pelo processo de biohidrogenação no rúmen dos animais, por ação de enzimas bacterianas (MARTIN et al., 2007; MAZOFFARIAN et al., 2006).

Os óleos vegetais polinsaturados de sementes como de soja, milho e canola representam uma fração importante da dieta humana e, nos últimos anos, o consumo destes óleos tem aumentado enquanto que o das gorduras de origem animal diminuiu. Ácidos graxos trans também se formam, em

Recebido para publicação em 18/1/2008

Aceito para publicação em 3/1/2009 (003156)

${ }^{1}$ Instituto Adolfo Lutz, Divisão de Bromatologia e Química, CP 1783, CEP 01059-970, São Paulo - SP, E-mail: spimente@ial.sp.gov.br

${ }^{2}$ Instituto Adolfo Lutz, Laboratório Regional I, Seção de Bromatologia e Química, Santos - SP

${ }^{*}$ A quem a correspondência deve ser enviada 
concentrações diminutas, nos óleos vegetais poli-insaturados submetidos à fritura e na etapa industrial de refino destes óleos. Sua formação está relacionada com o tipo de óleo, temperatura e tempo dos processos (MARTIN et al., 2007; SANIBAL; MANCINI-FILHO, 2004). Tem sido demonstrado que os AGT começam a se formar, por exemplo, em frituras com óleos vegetais poli-insaturados, em temperaturas a partir de $150{ }^{\circ} \mathrm{C}$, sendo que os teores aumentam significativamente acima de $250^{\circ} \mathrm{C}$. Em vários países da Europa a recomendação é de que a temperatura dos óleos de fritura não exceda a $180^{\circ} \mathrm{C}$ (MARTIN et al., 2007). No Brasil, a RDC 216/2004 da ANVISA (MINISTÉRIO DA SAÚDE, 2004) contém orientações aos preparadores de alimentos relacionadas às boas práticas de fabricação para uso e descarte de óleos utilizados em frituras e, também, limita a $180^{\circ} \mathrm{C}$ a temperatura durante o processo.

Óleos vegetais poli-insaturados devem passar por um processo de refino, para estarem adequados ao consumo humano. O processo de refino tem como objetivo remover substâncias mucilaginosas, ácidos graxos livres, pigmentos, odores e sabores indesejáveis (SHAHIDI, 2005). Por outro lado, pequena quantidade de ácidos graxos trans (AGT) é formada, particularmente, no estágio de desodorização do óleo (MARTIN et al., 2007). Os óleos vegetais brutos contêm quantidades mínimas de ácidos graxos trans, isto é, de 0,1 a $0,3 \%$ no total de ácidos graxos. Nas etapas de refino, prévias à desodorização, os níveis destes ácidos graxos permanecem baixos. Na desodorização com temperaturas ao redor de $230^{\circ} \mathrm{C}$ estes níveis elevam-se de três a dez vezes. São formados principalmente isômeros de ácidos graxos a partir daqueles com duas e três insaturações (18:2 e 18:3), pois estes apresentam maior reatividade nas condições de desodorização enquanto que os ácidos graxos monoinsaturados são os mais resistentes (Van BRUGGEN et al., 1998; DUCHATEAU; OOSTEN; VASCONCELOS, 1996). Neste caso, as duplas não mudam de posição e apenas uma dupla ligação isomeriza da forma cis para trans. A desodorização ocorre em temperaturas entre 180 e $260{ }^{\circ} \mathrm{C}$, sendo que abaixo de $200{ }^{\circ} \mathrm{C}$ pode-se evitar a formação de AGT (GROB, 2007). Entretanto, em condições de temperatura de desodorização extremas $\left(>250{ }^{\circ} \mathrm{C}\right)$ o nível daqueles ácidos graxos pode ser superior a 3\% (CERIANI; MEIRELLES, 2007; SCHWARZ, 2000; WOLFF, 1993).

No refino químico dos óleos vegetais, que é o processo mais empregado no Brasil, os ácidos graxos livres são neutralizados por intermédio da adição de hidróxido de sódio. O sabão formado é eliminado por lavagem com água e o óleo resultante é então branqueado e desodorizado. Entretanto, nos últimos anos, por razões econômicas, tem sido utilizado o processo de refino físico para óleos vegetais, principalmente para o óleo de soja. Neste processo, na etapa de desodorização, são eliminados os ácidos graxos livres, materiais insaponificáveis, dentre outros compostos (DUMONT; NARINE, 2007; CERIANI; MEIRELLES, 2006). Todavia, é necessário o emprego de temperaturas mais altas, isto é, de 210 a $230{ }^{\circ} \mathrm{C}$, uma vez que os ácidos graxos livres não são removidos previamente (STAAGE, 1985; CMOLIK et al., 2000). Esta operação requer menos investimento de capital e reduz a perda de óleo (DUMONT; NARINE, 2007).
O presente trabalho teve o objetivo de determinar os níveis de ácidos graxos trans em óleos refinados poli-insaturados comercializados no Estado de São Paulo, principalmente os de soja, sendo estes amplamente consumidos pela população e, assim, alertar as indústrias sobre a necessidade de melhorias no processo de refino daqueles óleos. Adicionalmente, foi avaliado o processo analítico para a preparação de ésteres metílicos de ácidos graxos a frio e o da análise cromatográfica dos ácidos graxos, inclusive trans, nos óleos vegetais refinados.

\section{Material e métodos}

Foram analisadas 34 amostras de óleo de soja, 7 de girassol, 2 de canola e 6 de milho de diferentes marcas e/ou lotes. As amostras foram coletadas no comércio do Estado de São Paulo e analisadas entre os anos de 2005 e 2007. As análises da composição de ácidos graxos foram feitas no Instituto Adolfo Lutz, em São Paulo, por cromatografia em fase gasosa. Os ácidos graxos dos óleos foram transformados em ésteres metílicos de ácidos graxos (EMAG), por transesterificação alcalina empregando $\mathrm{KOH}$ metanólico 2 mol. $\mathrm{L}^{-1}$ a frio, segundo método IUPAC 2301(1987), com modificações (INSTITUTO ADOLFO LUTZ, 2005). Empregou-se coluna capilar de sílica fundida com fase estacionária não ligada de bisciano propilpolisiloxano de $100 \mathrm{~m}$, com diâmetro interno de $0,25 \mathrm{~mm}$ e espessura do filme de $0,20 \mathrm{~mm}$ (SP 2560). A programação cromatográfica foi otimizada pela análise de amostra de óleo vegetal, fornecida pelo Conselho Oleícola Internacional (Espanha) com valores de referência para ácidos graxos, inclusive trans. Foram empregadas as seguintes condições: temperatura programada da coluna: $45^{\circ} \mathrm{C} ; 1^{\text {a }}$ rampa de aquecimento: $13^{\circ} \mathrm{C} / \mathrm{min}$ até $175^{\circ} \mathrm{C} ; 2^{\mathrm{a}}$ rampa: $4{ }^{\circ} \mathrm{C} / \mathrm{min}$ até $215^{\circ} \mathrm{C}$ (35 minutos).Temperatura do injetor e detector: $250{ }^{\circ} \mathrm{C}$, pressão na coluna: $175 \mathrm{kPa}$; gás de arraste: hidrogênio.

Os componentes foram identificados pela coinjeção de padrões e comparações com os tempos de retenção. Os padrões empregados foram os seguintes: mistura de 37 EMAG, variando de 4:0 a 24:0 átomos de carbono, marca SUPELCO, com quantidades certificadas de cada componente; mistura de EMAG isômeros cis-trans do ácido linoleico (18:2), mistura de EMAG isômeros cis-trans do ácido linolênico (18:3) e EMAG elaídico (18:1 9t), todos da marca Sigma. Os reagentes utilizados para a etapa de preparação dos EMAG foram de grau analítico: cloreto de sódio e hidróxido de potássio. Foram também utilizados os seguintes solventes de grau cromatográfico: $n$-hexano e metanol.

A avaliação da exatidão do método cromatográfico foi realizada por comparação dos valores de referência dos ácidos graxos e os obtidos experimentalmente utilizando o índice z-score, determinado pela Equação 1:

$$
\mathrm{z}=\frac{\left(X_{l a b}-X\right)}{\sigma}
$$

onde $X_{\text {lab }}$ = valor obtido pelo laboratório; $X=$ valor designado (melhor estimativa do valor verdadeiro); e s = valor alvo para o desvio padrão (variável dependendo do material de referência e definido de acordo com a precisão requerida). 
Valores de $-2<\mathrm{z}<2$ indicam desempenho satisfatório; $2<\mathrm{z}<3$, desempenho questionável; e $\mathrm{z}>3$ ou $\mathrm{z}<-3$, desempenho não satisfatório (AYRES et al., 2003; THOMPSON; WOOD, 1993).

\section{Resultados e discussão}

A determinação quantitativa de ácidos graxos trans em níveis muito baixos, como nos óleos vegetais, não é um procedimento simples. As concentrações destes ácidos variam normalmente entre 0 e $2 \%$ e os teores obtidos são, muitas vezes, utilizados na avaliação do processamento ou como critério de rejeição de produto nas transações comerciais. A análise naquela faixa de concentração requer a otimização dos parâmetros analíticos como tipo e temperatura da coluna, quantidade de amostra injetada, parâmetros de processamento dos picos, como mínima área, por exemplo. Tudo isso visa detectar picos de compostos com concentração de cerca de $0,01 \%$ (p/p de ésteres metílicos), isto é, com uma relação sinal/ruído maior que 3 (Van BRUGGEN et al., 1998). O método oficial AOCS Ce1h-05 é o recomendado para a determinação de ácidos graxos saturados, mono, poli e trans insaturados em óleos vegetais (AOCS, 2005). Entretanto, neste trabalho foi empregada uma programação que difere do método oficial e verificou-se sua adequação por intermédio da análise de uma amostra com valores de referência para alguns ácidos graxos, inclusive trans, enviada pelo Conselho Oleícola Internacional (COI 28/05).

A Tabela 1 apresenta os valores de referência e faixas de variação aceitáveis dos ácidos graxos da amostra COI28/05. Na Figura 1 está a representação gráfica do índice z-score com relação aos valores de referência de ácidos graxos da amostra COI 28/05, a qual foi analisada pelo método de metilação IUPAC 2.301 (1987), com modificações (INSTITUTO ADOLFO LUTZ, 2005), empregando a programação cromatográfica previamente descrita. Os resultados foram satisfatórios com valores no intervalo de $-2<\mathrm{z}<2$ (Figura 1 ).

Tabela 1. Valores de referência e faixas de variação aceitáveis de alguns ácidos graxos da amostra de referência.

\begin{tabular}{lccc}
\hline $\begin{array}{c}\text { Amostra/ácido } \\
\text { graxo }\end{array}$ & $\mathrm{X}$ & \multicolumn{1}{c}{$\sigma$} & $\mathrm{n}$ \\
\cline { 2 - 3 } & $\begin{array}{c}\text { (Valor } \\
\text { designado) }\end{array}$ & $\begin{array}{c}\text { (Valor alvo do } \\
\text { desvio padrão) }\end{array}$ & \\
\hline COI28/05 & & & \\
$16: 00$ & 10,06 & $0,12^{*}$ & 48 \\
$16: 01$ & 0,77 & $0,07^{\star}$ & 48 \\
$18: 00$ & 3,51 & $0,15^{*}$ & 48 \\
$18: 01$ & 75,7 & $0,84^{*}$ & 48 \\
$18: 02$ & 7,63 & $0,22^{\star}$ & 48 \\
$18: 03$ & 1,39 & $0,15^{*}$ & 48 \\
$20: 00$ & 0,4 & $0,04^{*}$ & 48 \\
$20: 01$ & 0,29 & $0,04^{*}$ & 48 \\
$22: 00$ & 0,13 & $0,04^{*}$ & 48 \\
$18: 1$ trans & 0,0175 & $0,018^{*}$ & 49 \\
$18: 2+18: 3$ trans & 0,2235 & $0,035^{\star}$ & 49 \\
\hline
\end{tabular}

n: número de laboratórios.*valores correspondentes a $3 \mathrm{~S}_{\mathrm{R}}$ do estudo interlaboratorial. $\mathrm{S}_{\mathrm{R}}$ desvio padrão da reprodutibilidade.
Os procedimentos oficiais para preparação de ésteres metílicos de ácidos graxos, recomendados pela AOAC e AOCS (AOAC, 2005; AOCS, 2005) utilizam como catalisador $\mathrm{BF}_{3}$ em metanol, o qual é tóxico, instável e pode formar produtos secundários, além da reação necessitar de aquecimento (CHRISTIE, 1993).

O método IUPAC 2.301, que emprega $\mathrm{KOH}$ metanólico como reagente de esterificação (IUPAC,1987; INSTITUTO ADOLFO LUTZ, 2005), apresenta restrições para sua aplicação na análise da gordura dos alimentos, pois não esterifica ácidos graxos livres; também, pode levar à formação destes ácidos por hidrólise, além de não esterificar a gordura de amostras com elevado teor de acidez (CHRISTIE, 1993; CHRISTOPHERSON; GLASS, 1969; KRAMER et al., 1997). Contudo, para amostras de óleos vegetais refinados, que contêm essencialmente triacilgliceróis e são praticamente isentas de ácidos graxos livres, fosfolipídios e outros lipídios polares, a transesterificação alcalina tem sido recomendada devido à simplicidade e rapidez (CHRISTOFERSON; GLASS, 1969; RATNAYAKE, 2004). A transesterificação alcalina com KOH metanólico 2 mol.L $\mathrm{L}^{-1}$ foi o procedimento empregado neste trabalho. Os resultados obtidos confirmam sua aplicabilidade para a análise de ácidos graxos, inclusive trans, em óleos vegetais refinados.

A Tabela 2 apresenta a faixa de variação da composição de ácidos graxos obtida nas amostras comerciais de óleos de soja (34), girassol (7), canola (2) e milho (6). Verificou-se que 16 amostras de óleo de soja, 2 de canola e 4 de girassol apresentaram níveis de ácidos graxos trans acima de 2,0\% ( $\mathrm{p} / \mathrm{p}$ de ésteres metílicos). Os principais ácidos graxos trans formados continham de duas a três insaturações, 18:2 e 18:3, respectivamente. Observou-se que em cerca de $50 \%$ das amostras de óleo de soja os níveis de ácidos graxos trans foram superiores aos $2 \%$, sendo que este óleo é muito consumido no Brasil, devido principalmente ao seu baixo custo. Apesar de os óleos de milho conterem altos teores de ácidos graxos poli-insaturados, não foram observados valores acima de $2 \%$ de AGT (p/p ésteres metílicos). Tais resultados podem ser decorrentes de um melhor controle das temperaturas de desodorização do processo de refino, mas também, devido à alta estabilidade do óleo de milho que contém antioxidantes naturais e apresenta mais de $98 \%$ dos ácidos graxos insaturados na posição 2 do triacilglicerol, sendo esta localização da molécula mais protegida de reações de oxidações e isomerizações (OLIVEIRA, 2001).

A Figura 2 apresenta o cromatograma de ácidos graxos obtido pela análise por CG-DIC de óleo de soja refinado analisado na coluna SP 2560 de 100 m. Nesta Figura são indicados os ácidos graxos, inclusive os de configuração geométrica trans.

Dentre os óleos vegetais comestíveis, o azeite de oliva é o único que apresenta faixas estabelecidas em norma Codex para os teores de ácidos graxos trans, de acordo com a categoria do azeite (CODEX ALIMENTARIUS, 2003). Para a categoria azeite de oliva, os limites são: $18: 1 t<0,20 \%$ e $18: 2+18: 3 t<0,30 \%$ ( $\mathrm{p} / \mathrm{p}$ de ésteres metílicos); já, para o azeite de oliva virgem, que não sofre processo industrial de refino, os limites são inferiores, isto é: C18: $1 t$ pode variar de 0,00 a 0,05\% e C18:2 + C18:3t de 0,00 a $0,05 \%$. 


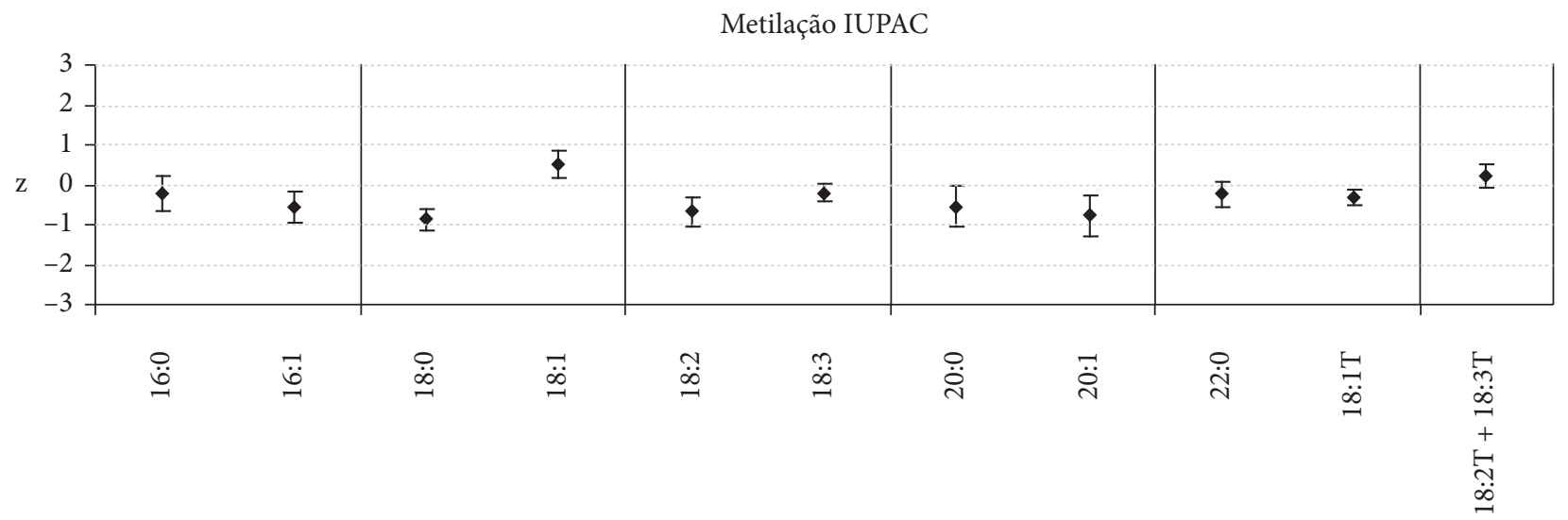

Figura 1. Representação gráfica do índice z-score com relação aos valores de referência de ácidos graxos da amostra COI 28/05, analisada pelo método de metilação IUPAC 2.301 , empregando as seguintes condições cromatográficas: coluna SP 2560, 100 m; programação de temperatura da coluna: $45^{\circ} \mathrm{C}$; $1^{\text {a }}$ rampa $13^{\circ} \mathrm{C} / \mathrm{min}$ até $175^{\circ} \mathrm{C}$, $2^{\text {a }}$ rampa $4{ }^{\circ} \mathrm{C} / \mathrm{min}$ até $215^{\circ} \mathrm{C}\left(35\right.$ minutos); temperatura do injetor e detector: $250{ }^{\circ} \mathrm{C}$; pressão na coluna: $175 \mathrm{kPa}$; gás de arraste: hidrogênio.

Tabela 2. Faixa de variação da composição de ácidos graxos de amostras de óleos vegetais refinados (soja, girassol, canola e milho) comercializados no Estado de São Paulo, entre os anos de 2005 e 2007.

\begin{tabular}{|c|c|c|c|c|}
\hline \multirow[t]{3}{*}{ Ácido graxo } & Óleo de soja & Óleo de girassol & Óleo de canola & Óleo de milho \\
\hline & $(n=34)$ & $(\mathrm{n}=7)$ & $(\mathrm{n}=2)$ & $(n=6)$ \\
\hline & \multicolumn{4}{|c|}{ Valores expressos em \% p/p de ésteres metílicos } \\
\hline $14: 0$ & $0,07-0,09$ & $0,07-0,14$ & $0,06-0,07$ & $0,04-0,05$ \\
\hline $15: 0$ & $0,01-0,02$ & $\mathrm{ND}^{*}-0,02$ & 0,02 & $\mathrm{ND}^{*}-0,01$ \\
\hline $16: 0$ & $10,27-12,17$ & $6,34-8,51$ & $5,00-5,38$ & $12,65-13,43$ \\
\hline $16: 1$ & $0,08-0,10$ & 0,11 & $0,21-0,24$ & $0,13-0,17$ \\
\hline $18: 0$ & $2,67-4,77$ & $3,10-3,97$ & $2,69-2,71$ & $2,37-2,49$ \\
\hline 18:1 cis & $22,57-25,82$ & $18,44-28,10$ & $59,88-60,85$ & $34,44-35,68$ \\
\hline $18: 1$ trans & $\mathrm{ND}^{\star}-0,18$ & $0,02-0,49$ & $0,06-0,07$ & $\mathrm{ND}^{*}-0,05$ \\
\hline $18: 2$ cis & $48,11-54,65$ & $55,66-63,11$ & $19,83-20,85$ & $42,23-44,90$ \\
\hline $18: 2$ trans & $0,29-2,75$ & $0,22-5,10$ & $1,06-1,08$ & $0,20-1,20$ \\
\hline Ácidos graxos trans & \multicolumn{4}{|c|}{ Valores expressos em g por porção de óleo } \\
\hline $18: 1$ trans & ND-0,02 & ND- 0,06 & $0,007-0,008$ & ND-0,006 \\
\hline 18:2 trans & $0,03-0,33$ & $0,03-0,60$ & $0,125-0,127$ & $0,02-0,14$ \\
\hline $18: 3$ trans & $0,04-0,32$ & $0,003-0,06$ & $0,25-0,38$ & $0,006-0,05$ \\
\hline trans total & $0,07-0,67$ & ND- 0,72 & $0,007-0,515$ & ND-0,196 \\
\hline
\end{tabular}

ND: não detectado $\left(\mathrm{ND}^{*}<0,01 \%\right)$. n: número de amostras. Porção $=13 \mathrm{~mL}$ de óleo.

Apesar dos demaisóleos vegetais comestíveis poli-insaturados não apresentarem valores estabelecidos para ácidos graxos trans em seus regulamentos técnicos, no Brasil, a RDC 360/2003 da ANVISA obriga a declaração dos níveis destes ácidos na rotulagem dos alimentos embalados. Os níveis de ácidos graxos trans são considerados insignificantes (declarado como zero na porção) quando inferiores a $0,2 \mathrm{~g}$ na porção. No caso de óleos vegetais foi estabelecido pela RDC 359/2003 da ANVISA (MINISTÉRIO DA SAÚDE, 2003b) que a porção apresentada na informação nutricional deve ser de $13 \mathrm{~mL}$ (ou uma colher de sopa) e, sendo assim, na rotulagem nutricional de várias amostras analisadas deverá constar valor superior a zero.

Na Tabela 2 os conteúdos dos ácidos graxos nas amostras analisadas estão expressos em \% p/p de ésteres metílicos de ácidos graxos enquanto os teores de ácidos graxos trans também foram calculados em g por $13 \mathrm{~mL}$ do óleo. Para o cálculo foi considerado que o óleo vegetal é composto essencialmente de triacilgliceróis e que um grama do óleo contém $0,956 \mathrm{~g}$ de ácidos graxos (McCANCE; WIDDOWSON'S, 2002). A densidade relativa média dos óleos a $20^{\circ} \mathrm{C}$, empregada no cálculo, foi de 


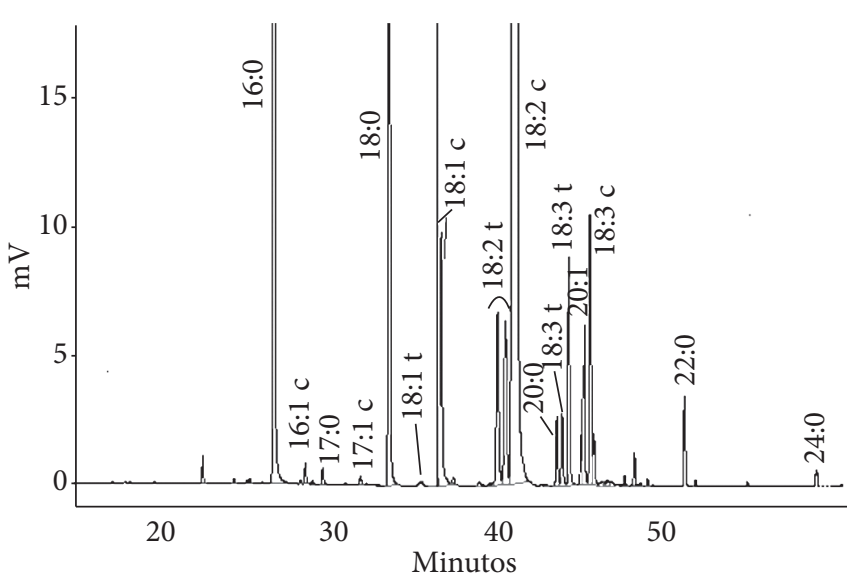

Figura 2. Cromatograma obtido pela análise por CG-DIC de óleo de soja refinado, analisado pelas seguintes condições cromatográficas: coluna SP 2560, $100 \mathrm{~m}$; programação de temperatura da coluna: $45^{\circ} \mathrm{C}$; $1^{\text {a }}$ rampa $13^{\circ} \mathrm{C} / \mathrm{min}$ até $175^{\circ} \mathrm{C}$, $2^{\text {a }}$ rampa $4{ }^{\circ} \mathrm{C} / \mathrm{min}$ até $215^{\circ} \mathrm{C}$ (35 minutos); temperatura do injetor e detector: $250{ }^{\circ} \mathrm{C}$; pressão na coluna: $175 \mathrm{kPa}$.

0,91 (Codex Alimentarius, 2005). Observa-se na Tabela 2 que, em algumas amostras, a somatória dos AGT supera o limite de $0,2 \mathrm{~g}$ por porção ( $13 \mathrm{~mL}$ de óleo), o que obriga a declaração dos teores destes compostos na informação nutricional de tais produtos. Neste caso, as informações constantes nos rótulos dos produtos apontam aspectos negativos do ponto de vista nutricional como também com relação ao processo tecnológico empregado.

Observou-se que nos rótulos das amostras que apresentaram teores de AGT acima de $0,2 \%$ (p/p de ésteres metílicos) não constava a declaração destes ácidos graxos na informação nutricional. No período da coleta das amostras (2005 a 2007), os produtos ainda estavam dentro do prazo de adequação dos rótulos permitido pela legislação. Entretanto, atualmente, no comércio são encontrados óleos vegetais refinados com alegações no rótulo como livres de ácidos graxos trans sendo que novos estudos devem ser desenvolvidos para avaliação destes produtos.

\section{Conclusões}

Dentre os óleos avaliados verificou-se que 16 amostras das 34 de óleo de soja, as 2 de canola e 4 das 7 de girassol apresentaram níveis de ácidos graxos trans acima de $0,2 \mathrm{~g}$ em 13 $\mathrm{mL}$ do óleo (porção) que é o limite da legislação de rotulagem nutricional para que os teores de trans sejam declarados como zero.

Os resultados obtidos indicam a necessidade de alteração nos processos industriais de refino dos óleos vegetais insaturados, como soja, canola e girassol, especialmente no controle das temperaturas de desodorização, o que poderá contribuir para atender às recomendações da Organização Mundial de Saúde no sentido de minimizar os níveis de ácidos graxos trans dos alimentos e, consequentemente, preservar a saúde da população.
O método de preparação de ésteres metílicos, que utiliza $\mathrm{KOH}$ metanólico a frio, bem como a programação cromatográfica empregada, mostrou desempenho adequado na determinação de AG, inclusive trans, nas amostras de óleo vegetal refinado de referência e nas comerciais analisadas.

O método de transesterificação alcalina mostrou-se rápido, barato e apropriado para aplicação nas análises de rotina para determinação da composição de ácidos graxos em óleos vegetais refinados.

\section{Agradecimentos}

À Fundação de Amparo à Pesquisa do Estado de São Paulo (FAPESP) pelo apoio financeiro.

\section{Referências bibliográficas}

American Oil Chemists' Society - AOCS. Official methods and recommended practices of the AOCS. 5 ed. Champaign, 2005. (Additions and revisions 1999-2006. Method Ce 1h-05. Determination of cis-, trans-, saturated, monounsaturated and polyunsaturated fatty acids in vegetable or non-ruminant animal oils and fats by capillary GLC).

Association of Oficial Analytical Chemists - AOAC. Official methods of analysis. 18 ed. Gaithersburg, 2005.

AYRES, M. et al. BioEstat. 3.0. Aplicações estatísticas nas áreas das ciências biológicas e médicas. Belém: Sociedade Civil Mamirauá; Brasília: CNPq, 2003.

CERIANI, R.; MEIRELLES, A. J. A. Formation of trans PUFA during deodorization of canola oil: a study through computational simulation. Chemical Engineering and Processing, v. 46, n. 9, p. 775-785, 2007.

CERIANI, R.; MEIRELLES, A. J. A. Simulation of continuous physical refiners for edible oil deacidification. Journal Food Engineering, v. 76, n. 8, p. 261-71, 2006.

CHRISTIE, W. W. Preparation of esters derivatives of fatty acids for chromatographic analysis. In: Advances in lipid methodology two. [S.L.]: [s.n.], 1993. p. 69-111. Disponível em: http://www.lipid. co.uk/infores/topics/methests/index.htm. Acesso em: Outubro 2004

CHRISTOPHERSON, S. W.; GLASS, R. L. Preparation of milk fat methyl esters by alcoholysis in an essentially nonalcoholic solution. Journal Dairy Science, v. 52, n. 8, p. 1289-90,1969.

CMOLIK, J. et al. Effects of plant scale alkali refining and physical refining on the quality of rapeseed oil. European Journal Lipid Science Technology, v. 102, n. 1, p. 15-22, 2000.

Codex Alimentarius Commission. Codex Standards for named vegetable oils, CODEX Stan 210, 1999. Roma: FAO/WHO, 2005. (Revisão 2005).

Codex Alimentarius Commission. Codex Standards for olive oils, and olive pomace oils, CODEX STAN 33, 1981. Rome: FAO/ WHO, 2003.

DUCHATEAU, G. S. M. L. E.; Van OOSTEN, H. J.; VASCONCELOS, M. A. Analysis of cis- and trans- fatty acid isomers in hydrogenated and refined vegetable oils by capillary gas-liquid chromatography. Journal American Oil Chemists' Society, v. 73, n. 3, p. 275-82, 1996.

DUMONT, M. J.; NARINE, S. S. Soapstock and deodorizer distillates from North American vegetable oils: Review on their 
characterization, extraction and utilization. Food Research International, v. 40, n. 8, p. 957-74, 2007.

HAWKE, C. Nutrition labels and health claims: the global regulatory environment. Genebra: World Health Organization, 2004.

Instituto Adolfo Lutz. Métodos físico-químicos para análise de alimentos. 4 ed. Brasília: ANVISA, 2005. 1018 p.

International Union of Pure and Applied Chemistry - IUPAC. Standard Methods for Analysis of Oils, Fats and Derivatives. Method 2.301; Report of IUPAC Working Group WG 2/87. 7 ed. [S.L.]: Blackwell Scientific Publications, 1987.

KRAMER, J. K. G. et al. Evaluating acid and base catalysis in the methylation of milk and rumen fatty acids with special emphasis on conjugated dienes and total trans fatty acids. Lipids, v. 32, n. 11, p. 1220-1228, 1997.

MARTIN, C. A. et al. Trans fatty acid-forming process in foods: a review. Anais da Academia Brasileira de Ciências, v. 79, n. 2, p. 1-8, 2007.

McCANCE AND WIDDOWSON'S. (Ed.). The composition of food. 6 ed. [S.L.]: Royal Society of Chemistry, 2002. 537 p.

MINISTÉRIO DA SAÚDE. Agência Nacional de Vigilância Sanitária. RDC n. 359, de 23 de dezembro de 2003b. Aprova regulamento técnico de porções de alimentos embalados para fins de rotulagem nutricional. Diário Oficial da República Federativa do Brasil, Brasília, n. 251, 26 de dezembro de 2003, Seção 1, p. 28.

MINISTÉRIO DA SAÚDE. Agência Nacional de Vigilância Sanitária. RDC n. 360, de 23 de dezembro de 2003a. Aprova regulamento técnico sobre rotulagem nutricional de alimentos embalados, tornando obrigatória a rotulagem nutricional. Diário Oficial da República Federativa do Brasil, Brasília, n. 251, 26 de dezembro de 2003, Seção 1, p. 33.

MINISTÉRIO DA SAÚDE. Secretaria de Vigilância Sanitária. RDC n. 216, de 15 de setembro de 2004. Dispõe sobre Regulamento Técnico de Boas Práticas para Serviços de Alimentação. Disponível em:<http://www.anvisa.gov.br/e-legis/>. Acesso em: 30 Março 2005.

MOZAFFARIAN, D. et al. Trans fatty acids and cardiovascular disease. New England Journal of Medicine, v. 354, n. 15, p. 1601-13, 2006.
OLIVEIRA, C. G. Proposta de modelagem para clarificação de óleos vegetais -experimentos cinéticos e simulação do processo industrial. Santa Catarina, 2001. Dissertação (Mestrado em Engenharia Química e de Alimentos) - Universidade Federal de Santa Catarina.

ORGANIZACIÓN MUNDIAL DE LA SALUD - OMS. Dieta, nutrición y prevención de enfermedades crónicas. Ginebra, 2003. (Serie de informes técnicos / 916).

RATNAYAKE, W. M. N. Overview of methods for the determination of trans fatty acids by gas chromatography, silver-ion thin layer chromatography, silver-ion liquid chromatography and gas chromatography/mass spectrometry. Journal AOAC International, v. 87, n. 2 , p. $523-39,2004$.

SANIBAL, E. A. A.; MANCINI-FILHO, J. Perfil de ácidos graxos trans de óleos e gorduras hidrogenada de soja no processo de fritura. Ciência Tecnologia de Alimentos, v. 24, n. 1, p. 27-31, 2004.

SCHWARZ, W. Formation of trans polyalkenoic fatty acids during vegetable oil refining. European Journal of Lipid Science and Technology, v. 102, n. 10, p. 648-649, 2000.

SHAHIDI, F. Bailey's Industrial Oil and Fat Products. 6 ed. New York: John Wiley \& Sons, 2005.

STAAGE, H. The physical refining process. Journal American Oil Chemists' Society, v. 62, n. 2, p. 299-308, 1985.

THOMPSON, M.; WOOD, R. International harmonized protocol for proficiency of (chemical) analytical laboratories. Journal AOAC International, v. 76, n. 4, p. 926-40, 1993.

Van BRUGGEN, P. C. et al. Precision of low trans fatty acid level determination in refined oils. Results of a collaborative capillary gas-liquid chromatography study. Journal American Oil Chemists' Society, v. 75, n. 4, p. 483-88, 1998.

WOLFF, R. L. Heat induced geometrical isomerization of alfa-linolenic acid effect of temperature and heating time on the appearance of individual isomers. Journal American Oil Chemists' Society, v. 70, n. 4, p. 425-30, 1993. 